\title{
$\mu$-Opioid Receptor Activation Reduces Multiple Components of High-Threshold Calcium Current in Rat Sensory Neurons
}

\author{
Konstantin I. Rusin and Hylan C. Moises \\ Department of Physiology, The University of Michigan, Ann Arbor, Michigan 48109-0622
}

\begin{abstract}
Whole-cell patch-clamp recordings were used to characterize calcium channel types that are modulated by $\mu-0-$ pioid receptor activation in rat dorsal root ganglion (DRG) neurons. Five distinct components of high-threshold calcium current were isolated on the basis of their sensitivity to the selective channel blockers $\omega$-conotoxin GVIA, nifedipine, $\omega$-conotoxin MVIIC, or $\omega$-agatoxin IVA. The $\mu$-opioid selective agonist Tyr-Pro-NMePhe-D-Pro-NH ${ }_{2}$ (PLO17) routinely suppressed high-threshold currents and this effect was always reduced by $\omega$-conotoxin GVIA. A fraction of PLO17-sensitive current remained after $\omega$-conotoxin GVIA that was eliminated by application of $\omega$-agatoxin IVA alone or in combination with w-conotoxin MVIIC. Nifedipine had no effect on $\mu$-opioid responses nor did PLO17 affect the slow component of tail current induced by Bay K 8644 . These data suggest that $\mu$-opioid receptors are negatively coupled to three types of calcium channels in rat DRG neurons, including an $\omega$-conotoxin GVIA-sensitive ( $\mathrm{N}$-type) channel, an $\omega$-agatoxin IVA-sensitive (P-type) channel and an $\omega$-conotoxin MVIIC-sensitive, nifedipine/GVIA/ $\omega$-Aga IVA-resistant (presumptive Q-type) channel.
\end{abstract}

[Key words: $\mu$-opioid receptors, high-threshold calcium current, $\omega$-conotoxin GVIA, $\omega$-agatoxin IVA, nifedipine, $\omega$-conotoxin MVIIC]

Mammalian neurons have been shown to express multiple types of calcium channels which can be conveniently classified into two major groups according to their voltage dependent properties. One type of low-threshold or T-type channels and at least three types of high-threshold channels, often termed N-, L-, and P-type, have been distinguished on the basis of their electrophysiological and pharmacological properties (Bean, 1989; Plummer et al., 1989; Hess, 1990; Tsien et al., 1991; Miller, 1992; Mintz et al., 1992a,b). The recent molecular characterization and functional expression of calcium channel clones from a variety of species have confirmed the existence of distinct $\omega$-conotoxin GVIA (GVIA)-sensitive N-type, dihydropyridinesensitive L-type and low-threshold T-type channels (Dubel et al., 1992; Gundersen and Umbach, 1992; Snutch and Reiner,

\footnotetext{
Received May 31, 1994; revised Dec. 22, 1994; accepted Jan. 30, 1995.

We thank Ms. Rebecca Piltch and Dr. Xiaoming Hou for providing technical assistance. We would also like to thank Pfiser, Inc., for their generous gift of $\omega$-agatoxin IVA. This work was supported in part by National Institute on Drug Abuse Grants DA03365 to H.C.M. and DA07268 (postdoctoral training fellowship) to K.I.R.

Correspondence should be addressed to Dr. Konstantin I. Rusin, Department of Physiology, University of Michigan Medical School, Ann Arbor, MI 48109. 0622 .

Copyright (C) 1995 Society for Neuroscience 0270-6474/95/154315-13\$05.00/0
}

1992; Williams et al., 1992a,b). P-Type channels, which provide the majority of high-threshold current in cerebellar Purkinje cells, have now been shown to represent a distinct class of channels in many central neurons (Regan et al., 1991; Mintz et al., 1992a,b). P-Type current demonstrates kinetic and voltage-dependent propertics similar to that of $\mathrm{N}$ - and L-types, but can be distinguished pharmacologically by its sensitivity to blockade by the funnel web spider toxin $\omega$-agatoxin IVA ( $\omega$-Aga IVA) (Mintz et al., 1992a,b). There is also evidence that neurons possess additional types of high-threshold currents that are resistant to $\mathrm{N}$ - ( $\omega$-conotoxin GVIA) and L-channel (dihydropyridine) blockers, but that differ from P-type current in their sensitivity to blockade by $\omega$-Aga IVA. Thus, Randall et al., (1993) have described a novel component of high-threshold current in cerebellar granule cells that coexists with $\mathrm{N}-, \mathrm{L}$-, and $\mathrm{P}$ type current, but differs from the latter in showing low sensitivity to blockade by $\omega$-Aga IVA and is blocked irreversibly by low micromolar concentrations of $\omega$-conotoxin MVIIC (MVIIC), purified from the venom of the marine fish-hunting snail Conus magus. Interestingly, it has recently been reported that the transfection of human $\alpha_{1 \mathrm{~A}}$ or rba-A channel clones into oocytes resulted in the expression of a high-threshold current with electrophysiological and pharmacological properties that resemble this so-called Q-type current (Zhang et al., 1993).

Opiates and the endogenous opioid peptides are among one of several major classes of drugs known to inhibit voltage-sensitive calcium channels in mammalian neurons. Work from this and other laboratories has shown that the activation of $\mu$ - or $\kappa$-opioid receptors suppresses several components of highthreshold calcium current in rodent sensory neurons, but does not affect T-current (Macdonald and Werz, 1986; Gross and Macdonald, 1987; Schroeder et al., 1991; Moises et al., 1994b). By means of their calcium channel inhibitory action opiates are thought to depress release of neurotransmitter from central endings of primary sensory afferent neurons and block transmission of nociceptive information entering CNS. Among the various types of calcium channels found in neurons, it is the N-type channels that are thought to provide the predominant target for inhibition by opiates, as well as by a variety of other inhibitory neurotransmitters and neuromodulators (for review, see Anwyl, 1991). However, recent studies have demonstrated the modulation of P type currents by GABA (Mintz and Bean, 1993) and adenosine (Mogul et al., 1993) and suppression of Q-type currents by 1S, 3R-ACPD, carbachol, 2-chloroadenosine, and (-)baclofen (Wheeler et al., 1993). Thus, it is possible that the depression of neurotransmitter release by opiates and other inhibitory neuromodulators might occur through suppression of activity of multiple types of high-threshold calcium channels, 
but this remains to be established at specific synapses within the CNS.

We have previously shown together with others that $\mu$-opioid receptor activation decreases high-threshold GVIA-sensitive (Ntype) calcium current in DRG neurons acutely isolated from adult rats (Schroeder et al., 1991; Moises et al., 1994b). In addition, we found that in many neurons, $\mu$-agonists reduce a fraction of high-threshold current that is resistant to blockade by saturating concentrations of GVIA and the L channel blocker nifedipine. To characterize the calcium channel types that might contribute the latter fraction of $\mu$-opioid-sensitive current we examined the effects of application of the $\mu$-opioid selective agonist Tyr-Pro-NMePhe-D-Pro-Nh $\mathrm{N}_{2}$ (PLO17) on high-threshold current components, isolated on the basis of their sensitivity to blockade by GVIA (N-type), nifedipine (L-type), MVIIC (Qtype), and $\omega$-Aga IVA (P-type). In addition, the possibility that $\mu$-opioid receptors modulate L-type channel activity was assessed directly by comparing the effects of the $\mu$-opioid on currents evoked in the absence and presence of the dihydropyridine agonist Bay K 8644. Here we report that $\mu$-opioid receptors are negatively coupled to three types of high-threshold calcium channels in rat DRG neurons, including a GVIA-sensitive (Ntype) channel, an $\omega$-Aga IVA-sensitive (P-type) channel and an MVIIC-sensitive, nifedipine/GVIA/ $\omega$-Aga IVA-resistant (presumptive Q-type) channel.

\section{Materials and Methods}

Preparation of acutely dissociated neurons. Acutely dissociated DRG neurons were prepared from 19-30 d old rats according to procedures described previously (Moises et al., 1994a,b). In brief, animals were sacrificed by $\mathrm{CO}_{2}$ inhalation, the sensory ganglia dissected from the lumbar and thoracic regions and placed in a culture dish containing minimal essential medium (MEM) with Earle's salts (GIBCO Laboratories, Grand Island, NY). The ganglia were treated for 50 min with collagenase (Type II, $3 \mathrm{mg} / \mathrm{ml}$, Sigma Chemical Co., St. Louis, Mo.) at $37^{\circ} \mathrm{C}$, after which a $1 \mathrm{ml}$ aliquot of medium containing trypsin Type I ( $1 \mathrm{mg} / \mathrm{ml}$, Sigma Chemical Co.) was added, and the incubation continued for an additional $10 \mathrm{~min}$. The dispersed ganglia were transferred to a conical tube containing $5 \%$ bovine serum albumin to inhibit the enzymes and centrifuged at $500 \times \mathrm{g}$ for $5 \mathrm{~min}$ at $4^{\circ} \mathrm{C}$. Dissociated ganglia were resuspended in fresh medium, centrifuged a second time $(5 \mathrm{~min}$ at $250 \times \mathrm{g}$ ) and then mechanically dispersed by triturating for 4-5 passages through a fire-polished Pasteur pipette. Cell suspensions were plated (approximately $200 \mu \mathrm{l} / \mathrm{dish}$ ) onto collagen-coated culture dishes and incubated at $37^{\circ} \mathrm{C}$ for $1 \mathrm{hr}$, after which an additional amount of MEM ( $2 \mathrm{ml} / \mathrm{dish}$ ) containing 10\% horse serum (Sigma Chemical Co.) and nerve growth factor $(50 \mathrm{ng} / \mathrm{ml}$, Boehringer Mannheim. Indianapolis, IN) was added. In roughly half of the experiments, neurons were studied between 2 and $8 \mathrm{hr}$ after plating, and in the remaining cases within the first $2 \mathrm{~d}$ in culture. DRG neurons maintained for more than $1 \mathrm{~d}$ in culture often began to extend processes and therefore were excluded from the analysis if the recordings showed any sign of inadequate space clamp (e.g., delayed settling of capacitance transient with time constants $>$ $150 \mu \mathrm{sec}$ and broad tail currents).

Whole-cell patch-clamp recordings. Voltage-clamp recordings were obtained using the whole-cell variation of the patch-clamp technique (Hamill et al., 1981). Glass recording patch pipettes (resistances of 1$2.5 \mathrm{M} \Omega$ ) were filled with recording solution of the following composition (in mM): $140 \mathrm{CsCl}, 10$ HEPES, 10 EGTA, 5 ATP (magnesium salt) and 0.1 GTP (lithium salt) (all reagents from Sigma Chemical). The pII was adjusted with $1 \mathrm{M} \mathrm{CsOH}$ to 7.2 after the addition of ATP and the osmolality (285-300 mOsm) adjusted to $10-15 \%$ below that of the bath solution. The neurons were bathed in a solution ( $\mathrm{pH} 7.4,315-$ $330 \mathrm{mOsm}$ ) consisting of (in mM) 67 choline chloride, 100 tetraethylammonium chloride, $5.3 \mathrm{KCl}, 5.6$ glucose, $2.0 \mathrm{BaCl}_{2}, 0.8 \mathrm{MgCl}_{2}$, and 10 HEPES. Under these conditions sodium and potassium currents were suppressed. Inward barium current through calcium channels will be referred to as calcium current. In the presence of $200 \mu \mathrm{M} \mathrm{Cd}{ }^{2+}$ to elim- inate the calcium currents, no voltage-dependent outward currents were evoked at test potentials as positive as $+30 \mathrm{mV}$.

Recordings were made at room temperature using an Axopatch 1-D patch-clamp amplifier (Axon Instruments, Foster City, CA). Pipette and whole-cell capacitance and series resistance were corrected using compensation circuitry on the patch-clamp amplifier. Initial input resistances were in the range of $500 \mathrm{M} \Omega$ to $1.2 \mathrm{G} \Omega$ and the series resistance was typically 1-3.5 M $\Omega$ In all cases, series resistance compensation of $80-$ $90 \%$ was possible without inducing significant noise or oscillation.

Voltage step commands of 30-100 msec duration were applied every $30 \mathrm{sec}$ and the evoked currents filtered with a 12-pole low pass Bessel filter at $10 \mathrm{kHz}(-3 \mathrm{~dB})$. The filtered current records were digitized at $5 \mathrm{kHz}$, stored and analyzed by a 386-based microcomputer using the program pCLAMP (Axon Instruments, Foster City, CA). Calcium currents were corrected for leak and capacitative currents using a $\mathrm{P} / 4$ routine which involved subtraction of an appropriately scaled current elicited by a series of four small hyperpolarizing steps, whose sum was equal in magnitude to the depolarizing test pulse.

Drug solutions and application. A rapid-exchange U-tube system (modified from Murase et al., 1989) was used to change the solution bathing the neuron under study. This consisted of a gravity fed U-shaped polyethylene tubing which generated a laminar flow of bathing solution across the neuron. The delivery port of the tube was positioned within $200 \mu \mathrm{m}$ of the neuron, while the distal end was interfaced to a vacuum line by means of a digitally controlled switching valve. Either control or drug solution flowed over the neuron throughout the recording, while the microenvironment around the cell could be rapidly exchanged $(<1$ $\mathrm{sec}$ ) by opening or closing the connection to the vacuum line.

PI.O17 (Peninsula I aboratories) was prepared as $1 \mathrm{~mm}$ stock solutions in sterile water, partitioned into $10 \mu \mathrm{l}$ aliquots, lyophilized and stored at $-20^{\circ} \mathrm{C}$. GVIA (Peninsula Laboratories), $\omega$-Aga IVA (Peptides International and Pfizer, Inc.) and MVIIC (Bachem California) were prepared as $500 \mu \mathrm{M}, 100 \mu \mathrm{M}$, and $1 \mathrm{mM}$ stock solutions, respectively, and stored in the same manner. On the day of the experiment aliquots of these channel blockers and freshly weighed amounts of nifedipine and Bay K 8644 (both from Research Biochemicals, Inc.) were dissolved in the extracellular bathing solution to the desired concentrations. To minimize degradation caused by exposure to light, nifedipine and Bay K 8644 were held in a light-proof container and routinely applied to the recording chamber under restricted light conditions. Solutions with GVIA, $\omega$-Aga IVA, or MVIIC also contained cytochrome C $(0.1 \%)$ to saturate peptide binding to containers.

Statistical comparisons. Results ohtained before and after administration of calcium channel blockers were compared statistically using the Student two-tailed $t$ test or repeated measures ANOVA followed by Tukey-Kramer multiple comparisons test. Values in text and figures are given as mean \pm SEM, unless otherwise indicated.

\section{Results}

$\omega$-Aga IVA selectivity

It was shown by Mintz and coworkers (1992a) that administration of purified $\omega$-Aga IVA at concentrations (100-200 nM) that are saturating for the inhibition of P-type channels does not affect T-type current nor $\mathrm{N}$ - and L-type currents in a variety of acutely isolated mammalian neurons, including DRG neurons. In the experiments reported here, we used a synthetic form of (s)-Aga IVA (obtained from Peptide International), and therefore sought first to determine the antagonist selectivity of this toxin for different components of calcium current in rat DRG neurons.

T-type currents were isolated by stepping to test potentials of

$-50 \mathrm{mV}$ to $-30 \mathrm{mV}$ from a holding potential of $-90 \mathrm{mV}$. Of the 133 neurons sampled, approximately $40 \%(n=53)$ had classical $\mathrm{T}$ currents which inactivated rapidly and whose maximal amplitudes comprised $5-20 \%$ of the total whole-cell current (Fig. 1 $A$, left). In 13 additional neurons voltage steps to the same range of test potentials evoked giant $\mathrm{T}$ currents (Fig. 1A, right). These resembled classical $T$ currents in their activation and inactivation properties but were of much larger amplitudes and accounted for $70-80 \%$ of the whole-cell current, as has been described previously (Schroeder et al., 1990; Scroggs and Fox, 
A

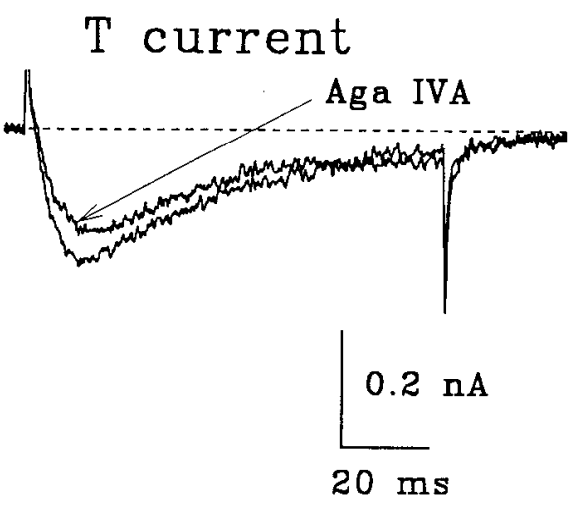

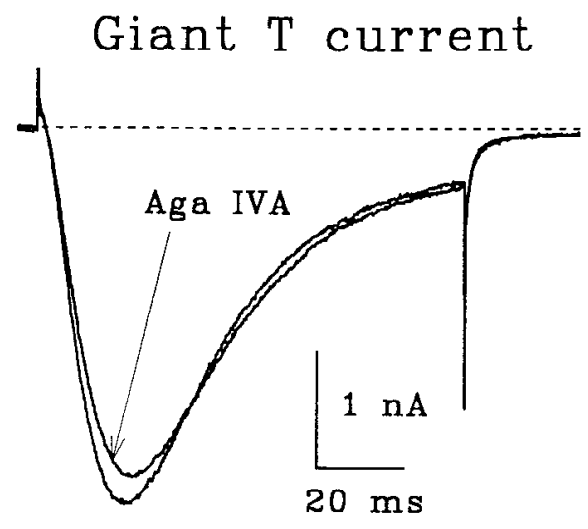

B

\section{L current}

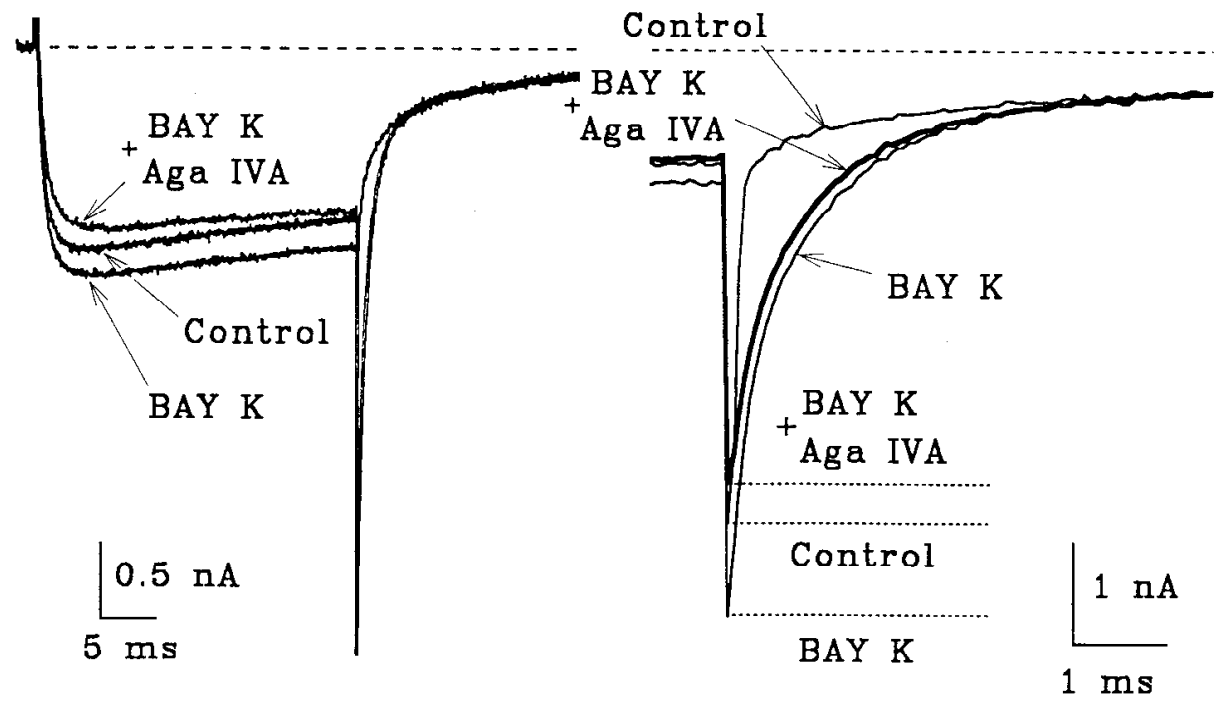

Figure I. Selectivity of $\omega$-Aga IVA block. $A$, Left and right pairs of traces illustrate classical and giant T-type currents elicited by a $100 \mathrm{msec}$ step from $-90 \mathrm{mV}$ to $-40 \mathrm{mV}$ in two different DRG neurons. These currents were reduced by $\omega$-Aga IVA $(200 \mathrm{nM})$ by $25.0 \%$ and $7.2 \%$, respectively. $B$, Current traces show that the dihydropyridine agonist Bay K 8644 (10 $\mu \mathrm{M})$ increased the amplitude of L-type current and induced a slow tail current through L-type channels. Administration of $\omega$-Aga IVA (200 nM) in the presence of Bay K 8644 reduced both the current during the test pulse (left) and the tail current (right) without affecting Bay K 8644-enhanced slow phase of tail current. Currents were elicited by a 30 msec step from $-80 \mathrm{mV}$ to $0 \mathrm{mV}$.

1992; Moises et al., 1994b). Administration of $\omega$-Aga IVA at concentrations above $50 \mathrm{~nm}$ reduced the peak amplitude of T current in all neurons tested $(n=7)$. When evoked in the presence of $200 \mathrm{nM} \omega$-Aga IVA, a concentration reported to be saturating for blockade of P-type channels (Mintz et al., 1992a), the amplitude of classical T currents was reduced by $17.7 \% \pm$ $3.4 \%$ (range, $11.8-25.0 \%, n=4$ ) and that of giant $\mathrm{T}$ currents by $9.7 \% \pm 1.7 \%$ (range, $7.2-12.9 \%, n=3$ ). Recovery of $\mathrm{T}$ current amplitudes to control levels was obtained within $1 \mathrm{~min}$ after washout of $\omega$-Aga IVA from the bath and delivery of a 15 $\mathrm{sec}$ train of depolarizing steps $(60 \mathrm{msec}$ to $+110 \mathrm{mV}$ at $2 \mathrm{~Hz})$ to the neuron. T currents were unaffected by administration of normal medium containing a carrier protein (cytochrome $\mathrm{C}$, $0.1 \%)$ but without toxin. Classical T currents $(n=5)$ and giant T currents $(n=7)$ were also unaffected by application of $\mu$-opioid agonists, confirming previous findings from this laboratory (Moises et al., 1994b). To simplify the analysis of the effects of $\omega$-Aga IVA on high-threshold current components, subsequent experiments were performed on neurons that did not express T-type channels.

To determine whether $\omega$-Aga IVA had an effect on L-type current we tested the ability of the toxin to modulate high-threshold currents that were enhanced by the dihydropyridine agonist Bay K 8644. The traces in Figure $1 B$ (left) show calcium currents elicited by $30 \mathrm{msec}$ steps to $0 \mathrm{mV}$ from a holding potential of $-80 \mathrm{mV}$ in control medium and in the presence of Bay $\mathrm{K}$ $8644(10 \mu \mathrm{M})$ alone and in combination with $\omega$-Aga IVA (200 $\mathrm{nM})$. The traces on the right in Figure $1 B$ are from the same experiment, but were recorded at a faster sampling rate to clearly illustrate tail current kinetics. Administration of Bay K 8644 increased the amplitude of the current during the test pulse and induced a characteristic slow component of tail current that has been attributed to prolonged openings of L-type channels (Nowycky et al., 1985). Application of $\omega$-Aga IVA in the presence of Bay K 8644 reduced the amplitude of the test pulse current as well as the peak amplitude of tail current (Fig. $1 B$, right). However, it did not affect the slow phase of tail current produced by Bay K 8644 . Similar results were obtained in three other neurons tested in this manner.

To determine whether $\mathrm{N}$-type currents were affected by $\omega$-Aga IVA we compared the amount of whole-cell current that was blocked by application of the toxin at $200 \mathrm{nM}$ before and after 


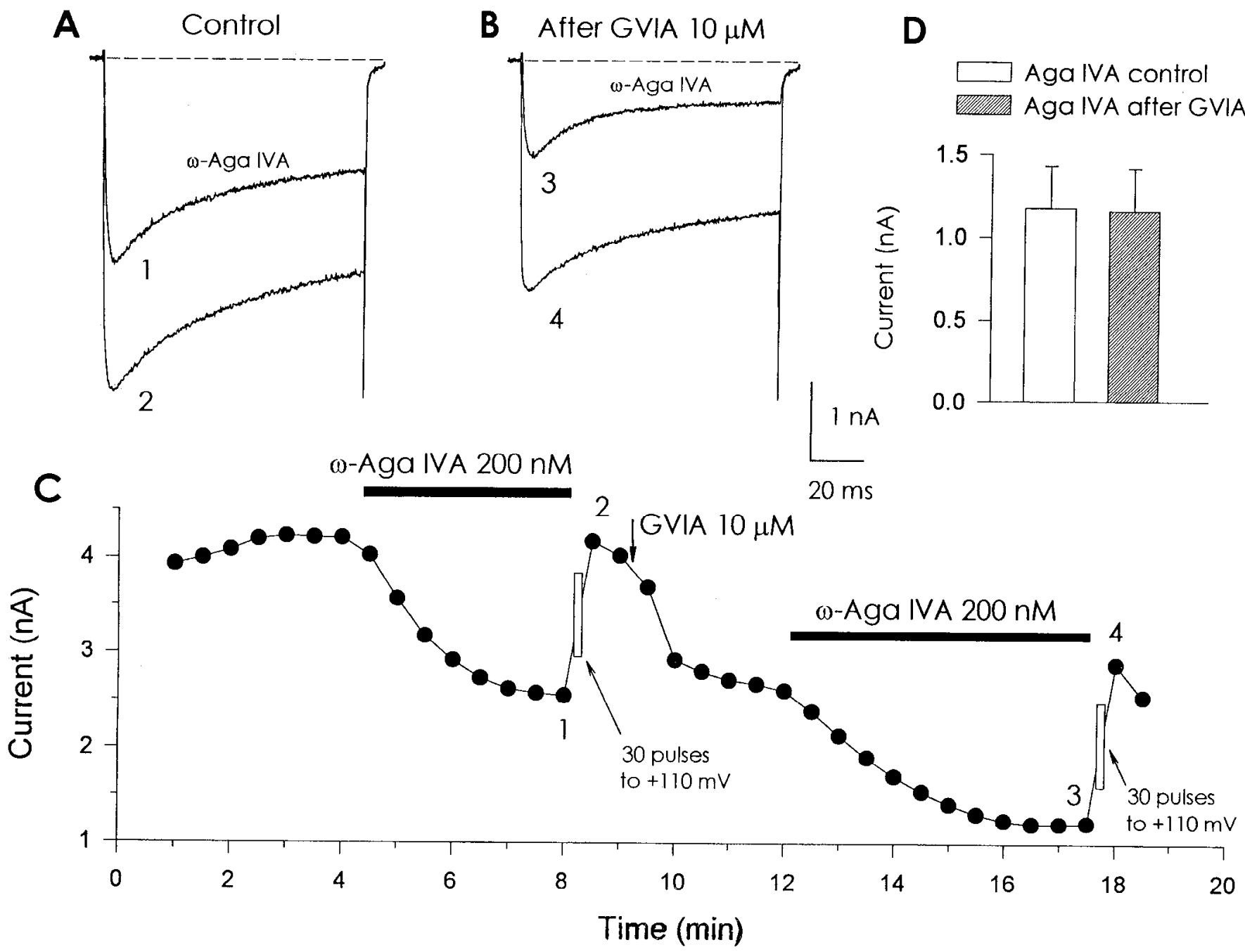

Figure 2. $\omega$-Aga IVA and GVIA inhibited distinct populations of calcium channels. $A$ and $B$, Calcium currents evoked by 100 msec steps to 0 $\mathrm{mV}$ from a holding potential of $-80 \mathrm{mV}$ at the times indicated in the graph $(C)$ of peak current versus experimental time, $\omega$-Aga IVA (200 nM) reduced the peak amplitude of the control current by $1.66 \mathrm{nA}$ when applied within the first 4 min after patch rupture and produced an equivalent suppression in current $(1.70 \mathrm{nA})$ when reapplied following establishment of irreversible blockade in current by GVIA (see text for details). Under both conditions, complete recovery of current blockade by $\omega$-Aga IVA was obtained after wash out of toxin and delivery of a train of 30 depolarizing steps to $+110 \mathrm{mV}(60 \mathrm{msec}$ duration at $2 \mathrm{~Hz})$. $D$, Comparison of mean $( \pm \mathrm{SEM})$ amount of current in nA that was inhibited by $\omega$-Aga IVA (200 $\mathrm{nM}$ ) when applied before (open bar) and after (hatched bar) GVIA $(10 \mu \mathrm{M})$ administration in six different neurons. There was no significant difference $(p=0.796$, paired $t$ test $)$ :

establishment of irreversible blockade of N-type current by saturating concentrations of GVIA $(10 \mu \mathrm{M})$. We reasoned that if $\omega$-Aga IVA and GVIA block different populations of calcium channels, then $\omega$-Aga IVA would suppress the same amount of whole-cell current whether or not N-type channels were blocked by GVIA. The traces in Figure $2, A$ and $B$, illustrate calcium currents from a typical experiment that were obtained using the protocol shown in the graph of peak current versus time after patch rupture depicted in Figure $2 \mathrm{C}$. Calcium currents were elicited by $100 \mathrm{msec}$ steps to $0 \mathrm{mV}$ from a holding potential of -80 $\mathrm{mV}$ every $30 \mathrm{sec}$. In this neuron, initial application of $\omega$-Aga IV $\Lambda$ (for $4 \mathrm{~min}$ ) within the first $5 \mathrm{~min}$ after patch rupture reduced the peak amplitude of the calcium current $39.4 \%$ from $4.21 \mathrm{nA}$ to $2.55 \mathrm{nA}(1.66 \mathrm{nA})$. Complete recovery of the current to the control level was obtained after wash out of the toxin and delivery of a train of 30 depolarizing steps (60 $\mathrm{msec}$ duration at 2 $\mathrm{Hz})$ to $+110 \mathrm{mV}$. GVIA $(10 \mu \mathrm{M})$ was then applied for $30 \mathrm{sec}$ and irreversibly reduced the whole-cell current by $30.0 \%$ from
$4.17 \mathrm{nA}$ to $2.92 \mathrm{nA}(1.25 \mathrm{nA})$. Application of $\omega$-Aga IVA (200 nM) subsequent to the establishment of the irreversible blockade by GVIA further reduced peak current amplitude by $1.70 \mathrm{nA}$ from $2.92 \mathrm{nA}$ to $1.22 \mathrm{nA}$, yielding an effect equivalent to that obtained prior to blockade of $\mathrm{N}$-type current by GVI $\Lambda$. The bar graph in Figure $2 D$ summarizes the results from six experiments which show that $\omega$-Aga IVA reduced calcium current by an equivalent amount when applied before $(1.17 \pm 0.26 \mathrm{nA})$ and after the inhibitory effect of GVIA had been established (1.15 $\pm 0.26 \mathrm{nA}, p=0.796)$. These data strongly suggest that distinct populations of calcium channels were inhibited by $\omega$-Aga IVA and GVIA. The fact that the inhibition in calcium current produced by the combined application of these toxins $(2.78 \pm 0.20$ $\mathrm{nA})$ was equal to the sum of their individual actions $(2.81 \mathrm{nA}$ total and $1.64 \pm 0.24 \mathrm{nA}$ for GVIA alone) indicated further that there was no overlap in the components of the current blocked by $\omega$-Aga IVA and GVIA as tested under our experimental conditions. 


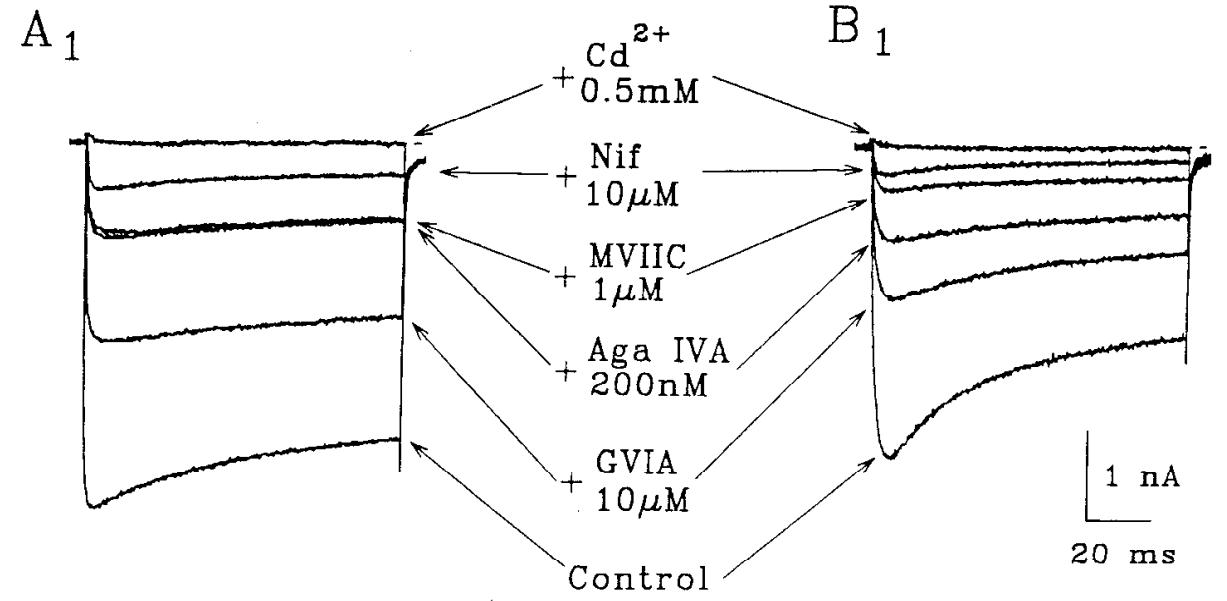

2

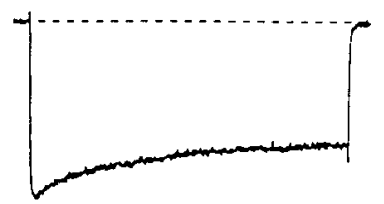

GVIA-sensitive

2

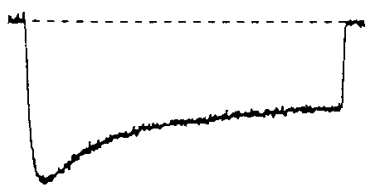

Aga IVA-sensitive

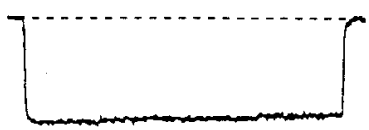

MVIIC-sensitive

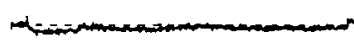

rensictive
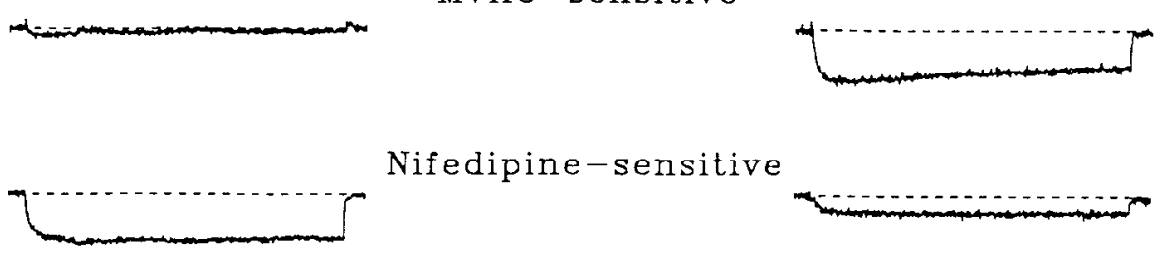

\section{Resistant component}
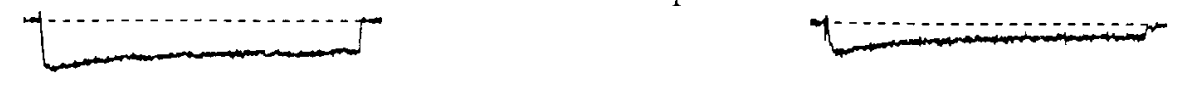

Figure 3. DRG neurons were distinguished by the presence or absence of a calcium current sensitive to MVIIC. $A_{1}$, Records from a neuron that did not express MVIIC-scnsitive (Q-like) calcium channels. $B_{l}$, Records from another neuron in which $16 \%$ of total high-threshold calcium current consisted of Q-like current that was sensitive to MVIIC. Currents were elicited by $100 \mathrm{msec}$ steps to $+10 \mathrm{mV}$ from holding potential of $-80 \mathrm{mV} . A_{2}$ and $B_{2}$, Subtraction of the traces before and after antagonists yielded GVIA-sensitive, $\omega$-Aga IVA-sensitive, MVIIC-sensitive and nifedipine-sensitive components as well as current resistant to all four calcium channel blockers.

\section{Pharrnacological separation of high-threshold carrents in rat DRG neurons}

The principal goal of this study was to identify the types of calcium channels, other than N-type, that contribute $\mu$-opioidsensitive high-threshold current in rat DRG neurons. As a first step in this analysis, we sought to describe distinct components of high-threshold calcium current that are present in these neurons by use of selective blockers for N-, P-, Q-, and L-type channels. The traces in Figure 3 illustrate results from typical experiments in two different neurons. In these experiments $(n=$ 27 ), calcium currents were elicited by $100 \mathrm{msec}$ steps to +10 $\mathrm{mV}$ from a holding potential of $-80 \mathrm{mV}$ every $30 \mathrm{sec}$. Following stabilization of the control current amplitudes, GVIA (10 $\mu \mathrm{M})$ was applied for $30 \mathrm{sec}$, which resulted in irreversible blockade of $35-55 \%$ of the whole-cell current and eliminated the major fraction of the rapidly inactivating components. Subtraction of the current trace recorded after GVIA application from the control current yielded an estimate of N-type current, as indi- cated by the traces labeled GVIA-sensitive in Figure $3, A_{2}$ and $B_{2}$. In the neuron shown in Figure $3 A$, GVIA inhibited $45.1 \%$ of the whole-cell current. The subsequent application of $\omega$-Aga IVA (200 $\mathrm{nM}$ for $4 \mathrm{~min}$ ) inhibited an additional $29.4 \%$ of the control current but had little effect on the inactivation kinetics of the GVIA-resistant current. Administration of MVIIC ( $1 \mu \mathrm{M}$ for $5 \mathrm{~min}$ ) in the continuing presence of $\omega$-Aga IVA had essentially no effect on the current that remained after GVIA and $\omega$-Aga IVA. However, this current was reduced by nifedipine (10 $\mu \mathrm{M}$ for $1 \mathrm{~min}$ ) with the dihydropyridine-sensitive component (L-type current) accounting for $9.8 \%$ of the control current. A significant fraction $(15.7 \%)$ of the whole-cell current was resistant to blockade by all four calcium channel blockers, but was eliminated by administration of $\mathrm{Cd}^{2+}(0.5 \mathrm{~mm})$, indicating that it was also carried through calcium channels. Subtraction of the current traces recorded before and after antagonist administration yielded the $\omega$-Aga IVA-, MVIIC-, and nifedipine-sensitive currents as well as the resistant component depicted in Figure 
$3 A_{2}$. Five of 27 neurons $(18.5 \%)$ demonstrated this pattern of sensitivity to calcium channel blockers, and thus appeared to express an unidentified resistant high-threshold channel in addition to N-, L-, and P-types.

The high-threshold currents elicited in the vast majority of DRG neurons ( $n=22,81.5 \%$ ) showed a different pattern of sensitivity to calcium channel antagonists, much like that illustrated for the neuron in Figure $3 B$. In this neuron sequential administration of GVIA, $\omega$-Aga IVA, MVIIC and nifedipine (in the manner described above) blocked $51.2 \%, 18.6 \%, 16.3 \%$, and $5.8 \%$ of the original control current, respectively. The fact that MVIIC blocked a substantial fraction of the current after the inhibitory effects of GVIA and $\omega$-Aga IVA were established suggested the presence in these neurons of an additional MVIICsensitive component of high-threshold calcium current that is not carried through $\mathrm{N}$ - or P-type channels. The latter component showed pharmacological sensitivity to calcium channel antagonists similar to that of a novel high-threshold calcium current, designated Q-type current by Tsien and coworkers, that has been described recently in rat cerebellar granule (Randall et al., 1993) and hippocampal neurons (Wheeler et al., 1994) and in Xenopus oocytes injected with $\alpha_{1 \mathrm{~A}}$ calcium channel clones (Sather et al., 1993). For purpose of this presentation, we will refer to this MVIIC-sensitive, dihydropyridine/GVIA/ $/$-Aga IVA-resistant component as a $\mathrm{Q}$-like current, with the understanding that its definitive assignment to a unique channel type requires additional information from single channel and kinetic analyses.

The inhibitory effect of $\omega$-Aga IVA (200 nM) on currents elicited after GVIA was found to be reversible in all neurons tested $(n=27)$, with recovery of current amplitudes to predrug levels obtained within 2 min after wash out of the toxin and delivery of a $15 \mathrm{sec}$ train of $60 \mathrm{msec}$ depolarizations to +110 $\mathrm{mV}$ at $2 \mathrm{~Hz}$. Without depolarizing pulse trains calcium currents showed very slow and incomplete recovery following washout of $\omega$-Aga IVA (also see Mintz et al., 1992a). On the other hand, when neurons $(n=27$ ) were exposed to MVIIC ( $1 \mu \mathrm{M})$ following the application of $\omega$-Aga IVA we were unable to obtain recovery upon washout of the toxins. Conversely, in a separate set of experiments ( $n=5$ ) $\omega$-Aga IVA $(200 \mathrm{~nm})$ had no effect on the residual component of current that remaincd following establishment of the inhibitory effect of MVIIC (data not shown). Thus, it appears that both $\mathrm{P}$ - and Q-like currents were blocked irreversibly by MVIIC in rat DRG neurons, as has been reported previously in rat Purkinje neurons (Hillyard et al., 1992).

We surmised from the results of experiments like those shown in Figure 3 that $\mathrm{N}^{-}, \mathrm{P}-, \mathrm{L}-$, and presumptive Q-type calcium channels account for different proportions of the high-threshold current in individual rat DRG neurons. To quantify the relative contribution of these individual current components to the total whole-cell current we averaged measurements of current amplitude blocked by each antagonist in neurons that were tested with a minimum of two different calcium channel blockers. Measurements of the reduction in the current amplitude produced by a given antagonist were pooled among neurons without regard to the sequential ordering of antagonist application. However, because MVIIC does not readily distinguish between $\mathrm{N}-, \mathrm{P}-$, and Q-type channels (Hillyard et al., 1992), estimates of Q-like current were obtained from the MVIIC-sensitive component that remained after blockade of $\mathrm{N}$ - and P-type channels by GVIA and $\omega$-Aga IVA, respectively. This analysis revealed that $42 \% \pm 5 \%(n=43)$ of high-threshold calcium current was con- tributed through GVIA-scnsitive N-type channels, $15 \% \pm 3 \%$ $(n=40)$ through dihydropyridine-sensitive L-type channels, $23 \% \pm 2 \%(n=33)$ through $\omega$-Aga IVA-sensitive P-type channels and $10 \% \pm 3 \%(n=27)$ through pharmacologically defined Q-type channels. In addition, $10 \% \pm 2 \%(n=27)$ of the high-threshold current in DRG neurons was contributed through an unidentified channel type(s) that was resistant to blockade by GVIA, dihydropyridines, MVIIC and $\omega$-Aga IVA.

\section{Identification of high-threshold currents sensitive to $\mu$-opioids}

To identify the types of high-threshold calcium channels to which $\mu$-opioid receptors are negatively coupled we examined the ability of PLO17 to reduce calcium current before and after selective blockade of N-, L-, and P-type and Q-like current components $(n=27)$. The traces in Figure $4 A$ illustrate the inhibitory effect of PLO17 ( $3 \mu \mathrm{M})$ on calcium currents evoked by 100 msec steps to $0 \mathrm{mV}$ from a holding potential of $-80 \mathrm{mV}$ at the times and under the conditions indicated in the current versus time graph depicted in Figure 4B. Application of PLO17 (for 30 $\mathrm{sec}$ ) within the first $6 \mathrm{~min}$ after patch rupture reduced the peak amplitude of the calcium current from $3.32 \mathrm{nA}$ to $2.11 \mathrm{nA}(1.21$ $\mathrm{nA}$ ), and this effect was completely reversed upon washout of the opioid. Following recovery from the inhibition in current by PLO17, GVIA $(10 \mu \mathrm{M})$ was administered for $30 \mathrm{sec}$. GVIA irreversibly suppressed the peak amplitude of the control current from $3.33 \mathrm{nA}$ to $1.71 \mathrm{nA}(1.62 \mathrm{nA}$, representing $48.6 \%$ of the control current), and after GVIA the fraction of current that was inhibited by PLO17 was reduced from $1.21 \mathrm{nA}$ to $0.32 \mathrm{nA}$ (representing $73.6 \%$ blockade). The application of $\omega$-Aga IVA (200 nM) subsequent to the establishment of the irreversible blockade by GVIA further reduced peak current amplitude from $1.71 \mathrm{nA}$ to $1.04 \mathrm{nA}$ (equivalent to $20.1 \%$ of the control current) and this was associated with a further reduction in the inhibitory response to PLO17 (from $0.32 \mathrm{nA}$ to $0.2 \mathrm{nA}$ ). Administration of MVIIC $(1 \mu \mathrm{M})$ in the presence of $\omega$-Aga IVA reduced wholecell current by an additional $0.54 \mathrm{nA}(16.2 \%)$ and abolished any effect of PLO17 that remained after $\omega$-Aga IVA. The application of nifedipine $(10 \mu \mathrm{M})$ in the continued presence of $\omega$-Aga IVA and MVIIC inhibited a fraction of the current that represented $5.4 \%(0.18 \mathrm{nA})$ of the original control current, whereas a cadmium-sensitive current that was resistant to blockade by the four antagonists contributed the remaining $9.6 \%(0.32 \mathrm{nA})$ of the current. The pairs of the traces depicted in Figure $4 A$ (second row) were obtained by subtraction of corresponding currents evoked before and after application of antagonists and illustrate sensitivity to PLO17 of pharmacologically distinguished N-type, P-lype, and Q-like current components. Overall, in 22 of 27 neurons $(81.5 \%)$ tested, the inhibition in calcium current by PLO17 showed sensitivity to blockade by selective calcium channel blockers like that illustrated for the neuron in Figure 4.

A different profile of sensitivity of $\mu$-opioid responses to calcium channel antagonists was found in the five remaining neurons. As illustrated for the neuron in Figure 5, administration of GVIA $(10 \mu \mathrm{M})$ irreversibly blocked a large fraction of the calcium current (from $5.25 \mathrm{nA}$ to $2.67 \mathrm{nA}$ representing $49.1 \%$ of control current) and reduced the PLO17-induced suppression in current by $81.2 \%$ (from $1.22 \mathrm{nA}$ to $0.23 \mathrm{nA}$ ). The application of $\omega$-Aga IVA (200 nM) subsequent to the establishment of N-type current blockade by GVIA further reduced the peak current amplitude from $2.67 \mathrm{nA}$ to $1.33 \mathrm{nA}$ ( $25.5 \%$ of control current) and abolished the inhibitory response to PLO17. Administration of MVIIC (1 $\mu \mathrm{M})$ in the continued presence of $\omega$-Aga IVA had 


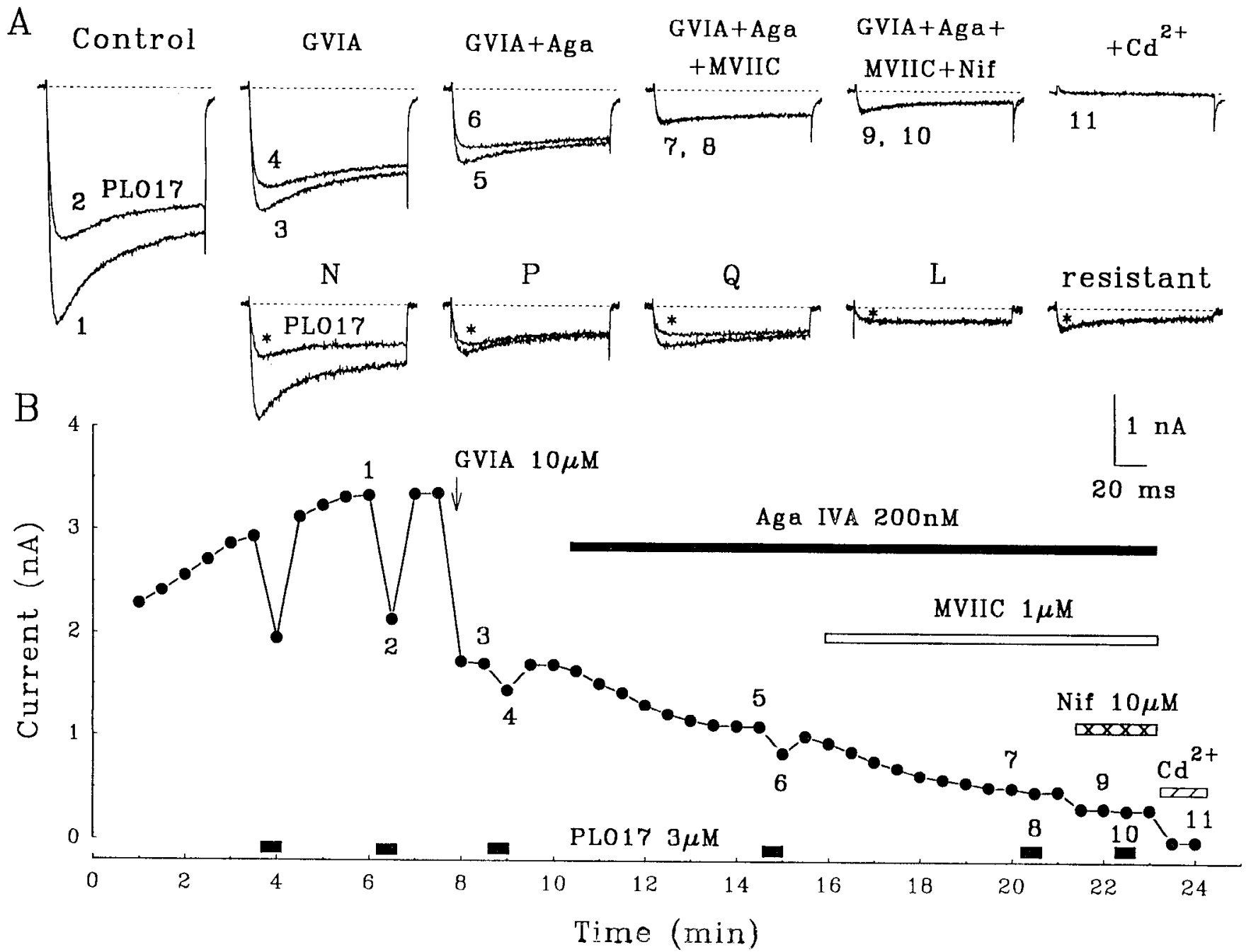

Figure 4. PLO17 inhibited GVIA-sensitive, $\omega$-Aga IVA-sensitive and MVIIC-sensitive calcium current components. A, Calcium currents evoked by $100 \mathrm{msec}$ steps to $0 \mathrm{mV}$ from a holding potential of $-80 \mathrm{mV}$ at the times indicated in the graph $(B)$ of current versus time after establish of the whole-cell configuration. Application of PLO17 $3 \mu \mathrm{M}$ for $30 \mathrm{sec}$ reduced total high-threshold calcium current. Administration of GVIA (10 $\mu \mathrm{M})$ for $30 \mathrm{sec}$ irreversibly reduced the total whole-cell current and the fraction of the current inhibited by PLO17. However, PLO17 continued to suppress a smaller fraction of the current that was resistant to GVIA. Administration of $\omega$-Aga IVA (200 nM) inhibited a portion of the remaining current and further reduce PLOl7-sensitive component. Administration of MVIIC $(1 \mu \mathrm{M})$ in the continuing presence of $\omega$-Aga IVA markedly reduced remaining current and virtually abolished the suppression in calcium current by PLO17. Application of nifedipine (10 $\mu \mathrm{M}$ ) inhibited a small portion of the remaining current. A:Second row, Subtraction of the currents recorded before and after antagonist applications yielded different current components blocked by the specific antagonist and PLO17-sensitive portion of these components.

virtually no effect on the whole-cell current. In contrast, application of nifedipine $(10 \mu \mathrm{M})$ in the presence of $\omega$-Aga IVA and MVIIC reduced the whole-cell current by $0.56 \mathrm{nA}$ (equivalent to $10.7 \%$ of control current). I astly, $13.7 \%$ of the control calcium current was resistant to blockade by all four antagonists and this unidentified current component was eliminated by the application of $\mathrm{Cd}^{2+}(0.5 \mathrm{~mm})$.

In previous studies (Moises et al., 1994a,b) we found that $\mu$-opioid-induced suppressions in calcium current remained stable with repeated applications of PLO17 over a 20-30 min period of whole-cell recording. Thus, it seemed unlikely that the failure of PLO17 to reduce GVIA-resistant current following administration of $200 \mathrm{nM} \omega$-Aga IVA alone $(n=5)$ or in the presence of $1 \mu \mathrm{M}$ MVIIC $(n=22)$ might be attributed to timedependent washout of the $\mu$-agonist-induced inhibitory effect. Nevertheless, to rule out this possibility an additional series of experiments was conducted in which responses to PLO17 were compared within the first 5-7 min of the patch rupture before and following the combined application of GVIA, $\omega$-Aga IVA and MVIIC. In these experiments $(n=6)$ initial application of PLO17 ( $3 \mu \mathrm{M}$ ) suppressed the peak amplitude of calcium current by $30.7 \pm 3.0 \%$, whereas there was virtually no effect of the $\mu$-opioid on calcium current that remained after administration of all three calcium channel blockers (data not shown). These data suggest that this residual fraction of high-threshold calcium current was contributed by channel type(s) that are not coupled to $\mu$-opioid receptors.

Figure 6 provides a graphical comparison of the average amount of calcium current inhibited by PLO17 (designated PLO17-sensitive current) under control conditions and following blockade of specific channel types by GVIA (N-type only), GVIA+ $\omega$-Aga IVA (N- and P-type) and GVIA+ $+\omega$-Aga IVA+MVIIC (N-, P-, and Q-type). The data depicted for each condition were obtained from the 27 neurons examined using 


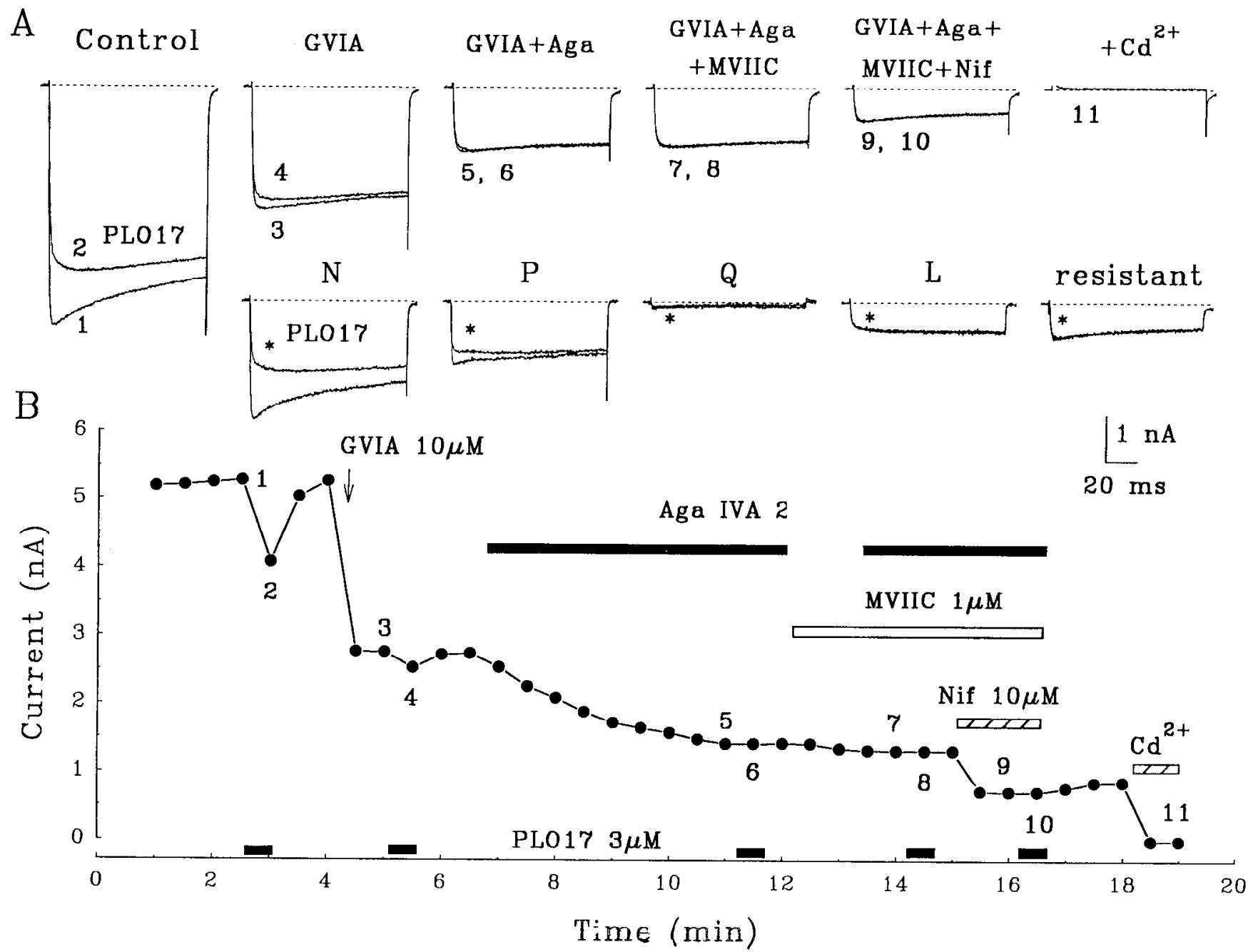

Figure 5. GVIA and $\omega$-Aga IVA eliminated PLO17-sensitive component in the neuron that do not express Q-like channels. A, Calcium currents evoked by $100 \mathrm{msec}$ steps to $0 \mathrm{mV}$ from a holding potential of $-80 \mathrm{mV}$ at the times indicated in the graph $(B)$ of current versus time after establish of the whole-cell configuration. Administration of PLO17 $3 \mu \mathrm{M}$ for $30 \mathrm{sec}$ reduced total high-threshold calcium current. Application of GVIA (10 $\mu \mathrm{M})$ for $30 \mathrm{sec}$ irreversibly blocked the fraction of total whole-cell current as well as the portion of the current inhibited by PLO17. However, PLO 17 continued to suppress a smaller fraction of the current that was resistant to GVIA. Administration of $\omega$-Aga IVA (200 nM) blocked a portion of GVIA-resistant calcium current and prevented PLO17 effect. Administration of nifedipine ( $10 \mu \mathrm{M})$ inhibited a small portion of the remaining current. A:Second row, Subtraction of the currents recorded before and after antagonist applications yielded different current components blocked by the specific antagonist and PLO17-sensitive portion of these components.

the same protocol as described for the experiments in Figures 4 and 5. Repeated measures ANOVA revealed a significant difference in the amount of PLO17-sensitive calcium current that was present under these four conditions $(F=126.52, p<$ $0.0001)$ with effective matching $(F=2.443, p=0.0013)$. In addition, post hoc analysis using the Tukey-Kramer multiple comparisons test showed that the inhibitory effect of PLO17 was reduced significantly following selective blockade of $\mathrm{N}-$, P-, and Q-like channels by the appropriate combination of antagonists. Thus, the amount of current inhibited by PLO17 averaged 0.39 $\pm 0.04 \mathrm{nA}$ after administration of a saturating concentration of GVIA ( $p<0.001$, compared to $1.23 \pm 0.10 \mathrm{nA}$ in control), and this was reduced further to $0.21+0.03 \mathrm{nA}$ and $0.02 \pm$ $0.01 \mathrm{nA}$, respectively, following application of $\omega$-Aga IVA without ( $p<0.05$, compared to effect after GVIA) and in combination with MVIIC ( $p<0.05$, compared to effect after GVIA $+\omega$-Aga IVA).

In the previous experiments, $\omega$-Aga IVA was administered at a high concentration $(200 \mathrm{nM})$ to achieve a relatively rapid and complete block of P-type channels (see for example Wheeler et al., 1994). However, studies in cerebellar granule neurons indicate that $\omega$-Aga IVA in concentrations above $30 \mathrm{~nm}$ can partially suppress Q-typc current, in addition to producing inhibition of all P-type current (Randall et al., 1993). Therefore, a separate series of experiments $(n=4)$ was performed to determine whether the activation of $\mu$-opioid receptors can inhibit a component of calcium current that is blocked by a low concentration of $\omega$-Aga IVA that selectively targets P-type channels. Neurons were preincubated in $\omega$-Aga IVA (30 nM) for $1 \mathrm{hr}$ prior to initiating whole-cell recording to achieve steady state blockade of P-type current. This was necessary because continuous administration of $\omega$-Aga IVA at concentrations below $50 \mathrm{~nm}$ failed to produce appreciable suppression of calcium current within the normal time frame $(20-25 \mathrm{~min})$ of whole-cell recording. We hypothesized that if $\mu$-opioid receptor activation inhibits $\mathrm{P}$-type current then washout from prolonged exposure to $\omega$-Aga IVA should recover an additional fraction of current that could be reversibly inhibited by PLO17. In three to four neurons a small, 


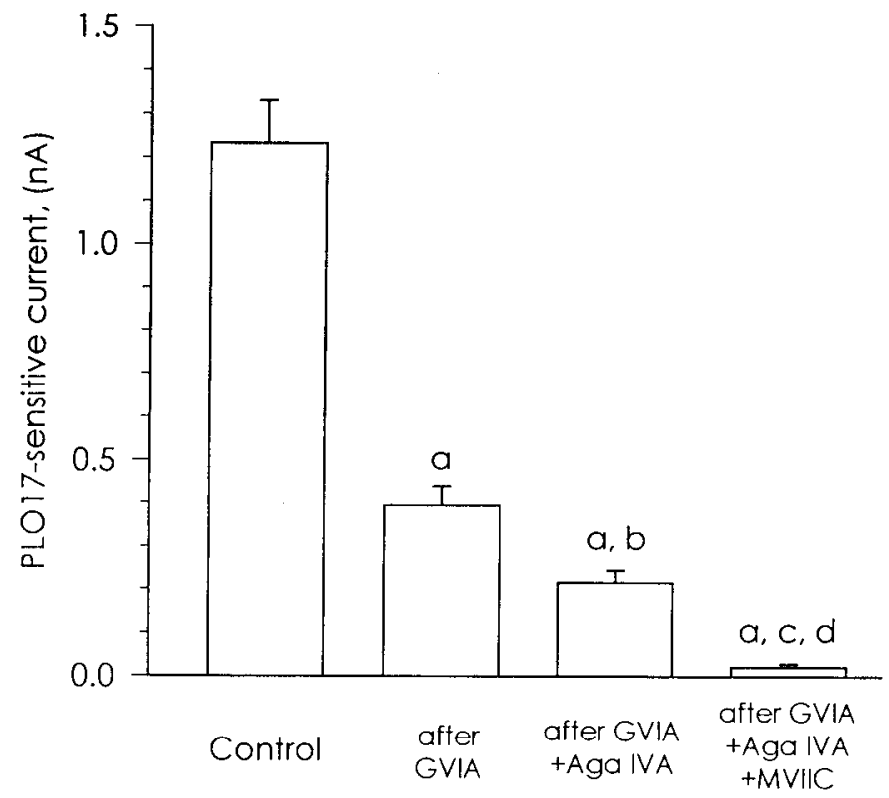

Figure 6. Effect of administration of GVIA alone and in combination with $\omega$-Aga IVA and MVIIC on PLO17-sensitive calcium current. The height of the bars indicates the mean amount (and capped lines SEM) of current in $\mathrm{nA}$ inhibited by PLO17 under control conditions $(1.23 \pm$ $0.10)$ and after administration of GVIA $(0.39 \pm 0.04)$, GVIA $+\omega$-Aga IVA $(0.21 \pm 0.03)$ and GVIA $+\omega$-Aga IVA + MVIIC $(0.02 \pm 0.01)$ Repeated measures ANOVA followed by post hoc analysis using the Tukey-Kramer multiple comparisons test revealed that the inhibitory effect of PLO17 was reduced significantly following selective blockade of $\mathrm{N}, \mathrm{P}$, and Q-like channel types by appropriate combination of antagonists: $a, p<0.001$ compared to control. $b, p<0.05$ compared to GVIA. $c, p<0.001$ compared to GVIA. $d, p<0.05$ compared to GVIA $+\omega$-Aga IVA.

slowly inactivating component of current was recovered shortly after washout of $\omega$-Aga IVA from the bath and delivery of a 30 pulse train of depolarizations (see Fig. 7). The recovered component, isolated by subtraction of calcium currents obtained in the presence of toxin from those evoked immediately after toxin washout, ranged in amplitude from 0.24 to $0.44 \mathrm{nA}$ and accounted for $4.8 \%$ to $8.1 \%$ of the total whole-cell current. In all three neurons, the increase in calcium current obtained upon relief of the $\omega$-Aga IVA-induced blockade was accompanied by an increase in the inhibitory response to PLO17. For example, in the experiment illustrated in Figure 7, peak current amplitude increased from $4.76 \mathrm{nA}$ in the presence of $\omega$-Aga IVA to 5.00 $\mathrm{nA}$ after washout of the antagonist $(\Delta=0.24 \mathrm{nA})$, whereas the amplitude of calcium current during the inhibitory response to PLO17 was only $0.12 \mathrm{nA}$ above the level (2.94 nA vs $2.82 \mathrm{nA}$ ) recorded when the opioid was applied in the presence of $\omega$-Aga IVA. Following the irreversible blockade of N-type current by GVIA, administration of MVIIC (1 $\mu \mathrm{M})$ further reduced the whole-cell current by $0.74 \mathrm{nA}$ (from $1.68 \mathrm{nA}$ to $9.4 \mathrm{nA}$ ) and completely eliminated the $\mu$-opioid effect. Since this concentration of MVIIC would be expected to block all P-type current, the preincubation for $1 \mathrm{hr}$ in $30 \mathrm{~nm} \omega$-Aga IVA must have blocked at least $30 \%$ of the P-type channels expressed in this neuron $(0.24 \mathrm{nA}$ of a maximum $0.74 \mathrm{nA})$. Similar results were obtained in the two remaining neurons in which the component of calcium current recovered after removal of $\omega$-Aga IVA (30 $\mathrm{nM})$ represented a larger fraction of the whole-cell current $(6.2 \%$ and $8.1 \%$ ).
Modulation of L-type calcium currents by PLO17 was investigated in a final series of five experiments. To determine whether $\mu$-opioid receptors are negatively coupled to L-type channels, we tested the ability of PLO17 to reduce the slow component of tail current induced by the dihydropyridine agonist Bay $\mathrm{K}$ 8644. The records in Figure $8 \mathrm{~A}$ show calcium currents elicited by $30 \mathrm{msec}$ steps to $0 \mathrm{mV}$ from a holding potential of $-80 \mathrm{mV}$ in control medium, in the presence of PLO17 $(3 \mu \mathrm{M})$ and during perfusion of bath solution containing Bay K $8644(10 \mu \mathrm{M})$. PLO17 reversibly reduced the amplitude of calcium current elicited during the test pulse as well as the peak amplitude of the tail current, but it did not alter tail current kinetics (Fig. 8A). In contrast, Bay K 8644 increased the amplitude of the test pulse current and induced a characteristic slow component of tail current (Fig. $8 A$, right). Figure $8 B$ shows calcium currents recorded in the continuous presence of Bay $K 8644(10 \mu \mathrm{M})$ from the same neuron as in Figure $8 A$. Administration of either GVIA $(10 \mu \mathrm{M})$ or PLO17 $(3 \mu \mathrm{M})$ reduced the amplitude of the test pulse current (Fig. 8B, left), as well as the amplitude of tail currents (Fig. $8 B$, right) that were elicited in the presence of the dihydropyridine agonist. However, neither the $\mu$-opioid nor GVIA affected the slow phase of tail current produced by Bay $\mathrm{K}$ 8644. Similar results were obtained in four other neurons tested in the same manner. These data suggest that activation of $\mu$-opioid receptors does not affect dihydropyridine-sensitive L-type calcium channels.

\section{Discussion}

\section{Selectivity of $\omega$-Aga IVA block}

Although earlier reports indicated that $\omega$-Aga IVA is a highly selective antagonist for P-type channels (Mintz et al., 1992a,b) we found that it had a small inhibitory effect on $T$ currents in rat DRG neurons. $T$ currents were reduced by $\omega$-Aga IVA in concentrations of $100-200 \mathrm{nM}$ which is within the range reported to produce complete suppression of P-type currents in these same neurons. The reduction in $\mathrm{T}$ current by $\omega$-Aga IVA was highly reproducible ( 7 out of 7 cells at $\omega$-Aga IVA concentration $200 \mathrm{nM}$ ) and exhibited properties that are characteristic of P-type current blockade by the toxin, including slow onset (2-3 min) and voltage dependent relief of blockade by delivering short trains of depolarizing stimuli (Mintz et al., 1992a).

Despite having some interaction with T-type channels, the selectivity of synthetic $\omega$-Aga IVA was maintained in the case of the L-type channels. Thus, administration of even high-concentration of the toxin (200 nM) had no effect on the characteristic slow component of the tail current that produced by Bay K 8644. Mintz and coauthors (1992a) have previously shown that the purified toxin also does not affect L-type calcium currents in rat DRG neurons. The question of whether synthetic $\omega$-Aga IVA discriminated completely between $\mathrm{P}$ - and N-type channels is more difficult to resolve on the basis of whole-cell recordings, because current components contributed by these channel types demonstrate similar kinetic and voltage-dependent properties (Regan et al., 1991). Nevertheless, we were able to show that there was no difference between the amount of wholecell current blocked by $\omega$-Aga IVA when tested before and after the inhibitory effect of a saturating concentration of GVIA had been established. Our data suggest that these toxins blocked distinct populations of channels even when administered in saturating concentrations as employed here.

Tsien and coauthors have described MVIIC as a potent blocker of Q-type calcium current in cerebellar granule neurons 


\section{A}

$\omega$-Aga IVA $30 \mathrm{nM}$

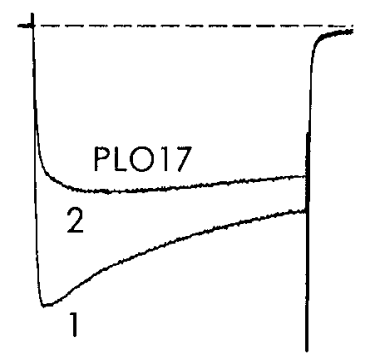

$$
\underbrace{\begin{array}{c}
1 \mathrm{nA} \\
0.5 \mathrm{nA}
\end{array}}_{20 \mathrm{~ms}}
$$

Control

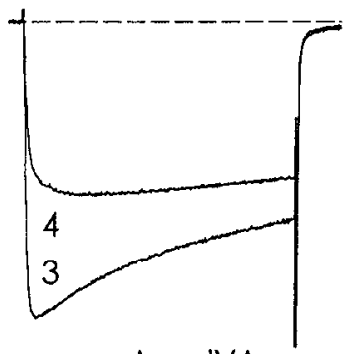

(1)-Aga IVAsensitive

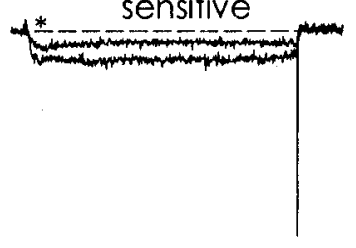

B

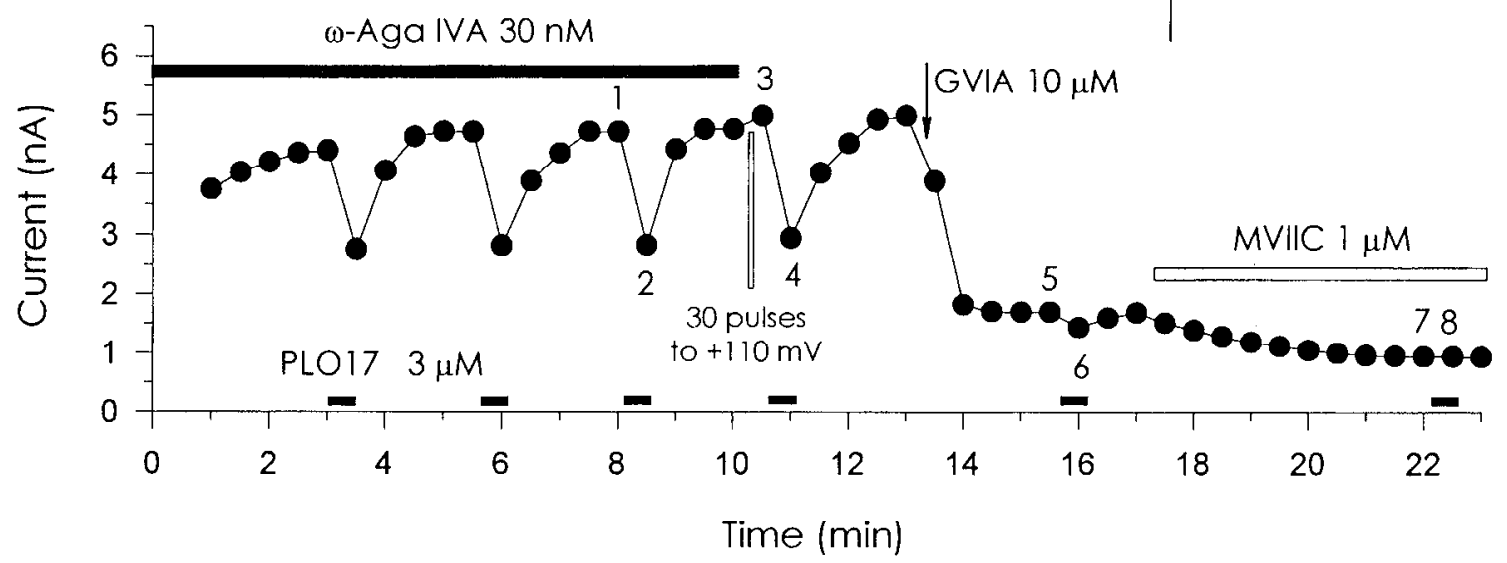

Figure 7. PLO17 inhibited a component of calcium current that was blocked by $\omega$-Aga IVA at concentration that selectively target P-type channels This neuron was incubated in $\omega$-Aga IVA $(30 \mathrm{nM})$ for $55 \mathrm{~min}$ prior to initiating whole-cell recording. $A$, Pairs of traces illustrate calcium currents evoked by $100 \mathrm{msec}$ steps to $0 \mathrm{mV}$ from a holding potential of $-80 \mathrm{mV}$ at the times indicated in the graph of peak current versus time after patch rupture depicted in $B$. Application of PLO17 $3 \mu \mathrm{M}$ for $30 \mathrm{sec}$ reduced the amplitude of calcium current evoked in the presence of $\omega$-Aga IVA (30 $\mathrm{nM}$ ) from $4.72 \mathrm{nA}$ to $2.82 \mathrm{nA}$. Washout of $\omega$-Aga IVA combined with delivery of a depolarizing train recovered a small, slowly inactivating component of current. Peak current amplitude increased from $4.76 \mathrm{nA}$ in the presence of $\omega$-Aga IVA to $5.00 \mathrm{nA}$ after washout of the antagonist $(\Delta=0.24 \mathrm{nA})$, whereas the amplitude of calcium current during the inhibitory response to PLO17 was only 0.12 nA above the level ( 2.94 nA vs $2.82 \mathrm{nA}$ ) recorded when the opioid was applied in the presence of $\omega$-Aga IVA. Following the irreversible inhibition in calcium current by GVIA (from $4.99 \mathrm{nA}$ to $1.69 \mathrm{nA}$ ), administration of MVIIC $(1 \mu \mathrm{M})$ further reduced the whole-cell current by $0.74 \mathrm{nA}$ (from $1.68 \mathrm{nA}$ to $9.4 \mathrm{nA}$ ) and completely eliminated the $\mu$-opioid effect. $A$, Traces depicted in lower row illustrate $\omega$-Aga IVA-, GVIA-, and MVIIC-sensitive current component obtained by subtraction of the currents recorded before and after antagonist applications. PLO17-sensitive portion of these components marked by asterisks. Note increase in scale to $0.5 \mathrm{nA}$ applies only for the $\omega$-Aga IVA $30 \mathrm{~nm}$-sensitive current.

(Randall et al., 1993). These authors defined Q-type current as an MVIIC-sensitive, nimodipine/GVIA/ $\omega$-Aga IVA-insensitive high-threshold current component which strongly resembles the current expressed by $\alpha_{1 A}$ calcium channel clones in Xenopus oocytes in its pharmacology, voltage- and time-dependence (Zhang et al., 1993). In cerebellar granule neurons, administration of $\omega$-Aga IVA in concentrations above $30 \mathrm{~nm}$ can partially suppress Q-type current, in addition to producing complete blockade of P-type current. Conversely, administration of MVIIC in high concentrations (above $1 \mu \mathrm{M}$ ) has been reported to inhibit P-type current in rat Purkinje neurons (Hillyard et al., 1992). The possibility that there might be some overlap in highthreshold current components blocked by $\omega$-Aga IVA and MVIIC in rat DRG neurons was not addressed in the present study. However, three observations were made that bear on this issue. First, a fraction of current that was sensitive to MVIIC (1 $\mu \mathrm{M})$ persisted after application of high concentrations of $\omega$-Aga IVA (200 nM) in 22 of 27 neurons. This suggests that under the conditions of our experiments $\omega$-Aga IVA did not completely block Q-like current. Second, no vollage-dependent relief from antagonist-induced current blockade was observed when administration of $\omega$-Aga IVA was followed by application of MVIIC. Third, there was no reduction in calcium current by $\omega$-Aga IVA $(200 \mathrm{nM})$ when it was applied after a suppression in current by MVIIC $(1 \mu \mathrm{M})$ was established. Thus, it seemed likely that MVIIC blocked at least some fraction of P-type channels in rat DRG neurons, as it has been shown to do in cerebellar Purkinje cells (Hillyard et al., 1992). Consequently, in those experiments 


\section{A Control medium}
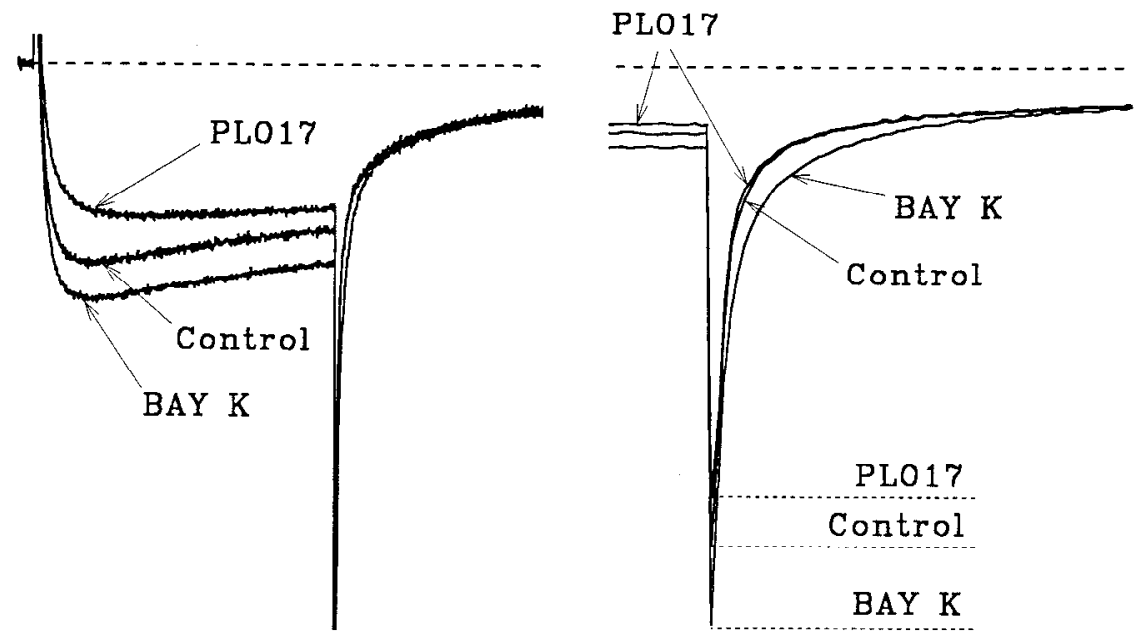

\section{$\mathrm{B}$ in $\mathrm{BAY} \mathrm{K} 8644$}

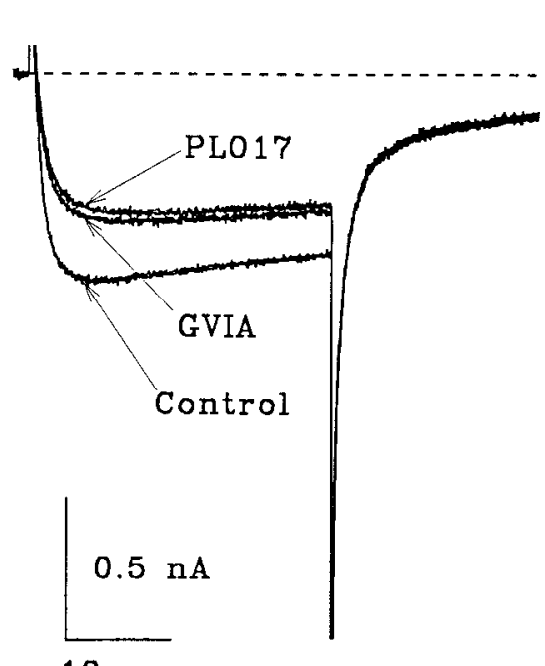

$10 \mathrm{~ms}$

\section{PL017}

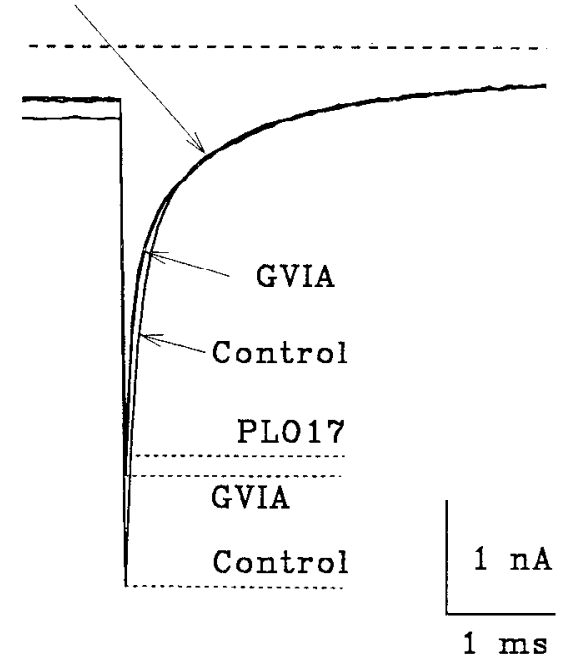

Figure 8. PLO17 and GVIA did not affect Bay K 8644-enhanced current in rat DRG neurons. $A$, Currents were elicited by depolarizing steps to $0 \mathrm{mV}$ from holding potential of $-80 \mathrm{mV}$. Administration of PLO17 (3 $\mu \mathrm{M})$ reduced whercas application of Bay K8644 (10 $\mu \mathrm{M})$ enhanced both test pulse current (left) and tail current (right), respectively. In addition Bay K 8644 induced a slow phase in the tail current. $B$, Currents elicited in the continues presence of Bay K 8644 from the same neuron as shown in $A$. Administration of GVIA $(10 \mu \mathrm{M})$ for $30 \mathrm{sec}$ suppressed both the test pulse current and the tail current amplitude. Application of PLO17 ( $3 \mu \mathrm{M})$ after GVIA produced further reduction in both test pulse current and tail current. In contrast, nether PLO17 nor GVIA had any effect on the slow phase of the tail current (right). where we used sequential application of antagonists to distinguish components of high-threshold current that were sensitive to $\mu$-opioids (see discussion below), MVIIC was always administered after blockade of P-type current by $\omega$-Aga IVA.

\section{DRG neurons express multiple types of high-threshold calcium channels}

The present results confirm and extend the findings of Mintz and coworkers (Mintz et al., 1992a; Mintz and Bean, 1993) that rat DRG neurons express at least four pharmacologically distinct types of high-threshold calcium channels. These investigators reported that approximately $43 \%$ of the high-threshold calcium current was contributed through GVIA-sensitive N-type channels, $18 \%$ by dihydropyridine-sensitive L-type channels, $23 \%$ by $\omega$-Aga IVA-sensitive P-type channels and that the remaining $18 \%$ was carried through an unidentified channel type that was GVIA-, dihydropyridine-, and $\omega$-Aga IVA-insensitive. Our results suggest that the latter current component consisted in part of an MVIIC-sensitive, $\omega$-Aga IVA-resistant Q-like current. This conclusion is based on the finding that MVIIC blocked a sizable fraction of the high-threshold calcium current that persisted after the combined application of GVIA, nifedipine, and $\omega$-Aga IVA in saturating concentrations. When the reductions in peak current amplitude produced by a particular antagonist were averaged across many neurons, we found that GVIA (10 $\mu \mathrm{M})$ irreversibly blocked approximately $42 \%$, $\omega$-Aga IVA (200 nM) suppressed $24 \%$, MVIIC ( $1 \mu \mathrm{M}$, tested after block of N-type channels by GVIA and in the presence of $\omega$-Aga IVA) blocked $10 \%$ and nifedipine $(10 \mu \mathrm{M})$ blocked $15 \%$ of the total high-threshold current in rat DRG neurons. In addition, approximately $10 \%$ of the high-threshold calcium current was found to be $\mathrm{Cd}^{2+}$-sensitive but resistant to blockade by all four calcium channel antagonists. The majority of DRG neurons sampled (22 of 27) displayed this general profile of high-threshold calcium current components, whereas the remaining five neurons appeared to express only N-, L-, P-, and a "resistant" type of high-threshold calcium current.

We are cognizant of the need for caution when the designation 
of channel types is assigned solely on the basis of these kinds of pharmacological criteria. Thus, there might be overlap in the blockade of calcium channel types by dihydropyridines and GVIA, as was found in chick sensory neurons where GVIA reversibly suppressed L-type calcium current in addition to producing an irreversible block of N-type currents (Aosaki and Kasai, 1989). Conversely, administration of dihydropyridines in high concentrations $(10 \mu \mathrm{M})$ has been reported to partially inhibit N-type current in rat DRG neurons (Regan et al., 1991). An additional concern is that $\omega$-Aga IVA and MVIIC are not completely selective for $\mathrm{P}$ - and Q-type channels, respectively, as mentioned above. It also should be noted that we did not take into account a possible contribution of rundown in current in the estimations of calcium current blockade produced by each of the antagonists. Typically, the long time required for sequential application of all four antagonists precluded the determination of a basal rate of current rundown, which in any event varied upon blockade of part of the current by antagonists. Therefore, we opted to express the fraction of current blocked by each antagonist as a percentage of peak amplitude of the control current and in so doing sought to minimize potential confounding effects attributable to current rundown by averaging the inhibitory effect of the drug across many neurons. While the percentages presented here for the relative contribution of Q-like, N-, L-, and P-type current components to the total highthreshold current in rat DRG neurons should he viewed, therefore, as approximations, they nevertheless conform quite closely with the values that have been reported by others (Mintz et al., 1992a).

\section{$\mu$-Opioids modulate three types of high-threshold calcium channels}

Previous work from this and other laboratories (Schroeder et al., 1991; Moises et al., 1994b) indicated that the profile of calcium current inhibition produced by $\mu$-opioid receptor activation in rat DRG sensory neurons can not be attributed to the modulation of a single type of calcium channel. This conclusion was based on the fact that administration of GVIA $(10 \mu \mathrm{M})$ always suppressed but was unable to completely eliminate the inhibition in calcium current by $\mu$-opioids in the majority of ncurons. Such data do not preclude the possibility that $\mu$-opioid receptors might regulate the activity of a subpopulation of $\mathrm{N}$-type channels that are not blocked by GVIA. However, we consider this unlikely and favor the first hypothesis, since the fraction of $\mu$-opioidsensitive current that persisted after GVIA administration could be eliminated by combined application of other calcium channel antagonists. Thus, in a small subset of DRG neurons (18.5\%) administration of the selective P-type channel blocker $\omega$-Aga IVA $(200 \mathrm{nM})$, eliminated inhibitory responses to PLO17 that remained after irreversible block of $\mathrm{N}$-type calcium channels by GVIA was established. These data suggest that $\mathrm{N}$ - and P-type calcium channels contribute $\mu$-opioid-sensitive current. Additional evidence that $\mu$-opioid receptors are negatively coupled to P-type channels was obtained from experiments in which the effects of PLO17 were examined on a component of calcium current unequivocally defined as P-type based on its sensitivity to blockade by $30 \mathrm{~nm} \omega$-Aga IVA. Thus, after neurons had been preincubated for $1 \mathrm{hr}$ in $30 \mathrm{nM} \omega$-Aga IVA, washout of the toxin recovered a small, slowly inactivating component of current (0.24-0.44 nA in amplitude, three of four neurons) and much of this additional current was reversibly suppressed by subsequent application of PLO17. Nonetheless, in most of the sensory neu- rons cxamincd $(81.5 \%) \mu$-opioid receptors also appeared to be negatively coupled to a third type of high-threshold calcium channel, since GVIA and $\omega$-Aga IVA administered in saturating concentrations failed to completely eliminate all of the $\mu$-opioidsensitive current. The pharmacological sensitivity of this residual component of $\mu$-opioid-sensitive current to blockade by MVIIC suggested that it might be contributed by the so-called Q-type chanmels first described by Tsien and coworkers (Randall et al., 1993). Overall, $\mu$-opioid receptors appeared to be differentially coupled to the three channels types with GVIA-sensitive calcium current (N-type) being most sensitive to modulation by PLO17. Administration of PLO17 in saturating concentrations inhibited $\mathrm{N}$-type current on average by $\sim 55 \%$, whereas $\omega$-Aga IVA-sensitive current (P-type) was reduced by $\sim 20 \%$ and MVIIC-sensitive (Q-like) current was inhibited by $\sim 30 \%$. The finding in rat peripheral sensory neurons that $\mu$-opioid receptors regulate activity of multiple high-threshold calcium current components is in keeping with a growing body of data which demonstrate modulation of other non- $\mathrm{N}$-type high-threshold calcium currents in central neurons by a variety of neurotransmitters and neuromodulators. For example, recent studies have demonstrated the inhibitory modulation of P-type currents by GABA in rat Purkinje neurons (Mintz and Bean, 1993) and enhancement of these currents by adenosine in guinea pig hippocampal neurons (Mogul et al., 1993). In addition, suppression of Q-type currents by carbachol, 2-chloroadenosine, $(-)$-baclofen and the metabotropic glutamate receptor agonist $1 \mathrm{~S}, 3 \mathrm{R}-\mathrm{ACPD}$ has been reported in rat hippocampal neurons (Wheeler et al., 1993).

In contrast, several lines of evidence were obtained which rule out L-type channels as targets of $\mu$-opioid receptor modulation in rat DRG neurons. First, the combined application of the selective calcium channel antagonists GVIA, $\omega$-Aga IVA and MVIIC completely eliminated suppression of high-threshold calcium currents by PLO17 in all neurons tested (Figs. 4, 5). Second, nifedipine by itself inhibited the whole-cell current without affecting $\mu$-opioid-induced inhibitory responses (Moises et al., 1994b). Third, PLO17 did not affect the characteristic slow phase of tail current produced by the dihydropyridine agonist Bay K 8644 (Fig. 8).

$\mu-, \delta-$, and $\kappa$-opioid reccptors belong to the superfamily of G-protein-coupled, seven-transmembrane spanning receptors and are known to share a high-degree of amino acid sequence homology (Meng et al., 1993; Thompson et al., 1993). The sequences that comprise the membrane spanning segments and intracellular loops are highly conserved among the three opioid receptor subtypes, suggesting that they might utilize similar signaling pathways. This study did not address the mechanism(s) through which $\mu$-opioid receptor activation produces suppression in calcium current. However, in a recent report (Moises et al., 1994a) we showed that the inhibition in calcium current by $\mu$-opioids in rat DRG neurons occurred through activation of a $\mathrm{G}_{\mathrm{o}}$ type GTP-binding protein. Thus, intracellular dialysis of neurons with an antisera specific for $\alpha$-subunits of $\mathrm{G}_{0}$-type $\mathrm{G}$-proteins greatly attenuated responses to $\mu$-opioids, whereas antibodies specific for $\alpha$ subunits of $G_{i 1}, G_{i 2}$ or $G_{i 3}$ were without effect. These data, together with the fact that pretreatment of neurons with pertussis toxin (PTX) completely eliminated the suppression in calcium current by $\mu$-opioids (Moises et al., 1994a), support the notion that the $G_{0}$ subclass of GTP-binding proteins mediate inhibitory coupling of $\mu$-opioid receptors to $\mathrm{N}$-type, P-type, and presumptive Q-type calcium channels in rat DRG neurons. 
In summary, we have shown that $\mu$-opioid receptors are negatively coupled to three types of high-threshold calcium channels in rat DRG neurons, including GVIA-sensitive (N-type), $\omega$-Aga IVA-sensitive (P-type) and MVIIC-sensitive (presumptive Q-type) channels. In contrast, dihydropyridine-sensitive (Ltype) channels and an unidentified, GVIA/dihydropyridine/ $\omega$ Aga IVA/MVIIC-resistant channel(s) were not affected by activation of $\mu$-opioid receptors. Much evidence suggests that GVIA-sensitive (N-type) calcium channels play an important role in impulse-dependent release of neurotransmitter at central junctions (see, for example, Dutar et al., 1989). Interestingly, GVIA does not completely block depolarization-evoked calcium entry into rat brain synaptosomes (Lundy et al., 1991; Mintz et al., 1992b), but this uptake is antagonized by MVIIC and $\omega$-Aga IVA. Thus, one might speculate that GVIA-insensitive calcium channels, such as $\mathrm{P}$ - and/or Q-type channels, participate together with GVIA-sensitive N-type channels in the voltage-dependent influx of calcium that couples nerve terminal depolarization to neurotransmitter release (Hillyard et al., 1992; Mintz et al., 1992b). The finding here that $\mu$-opioid agonists can suppress calcium current carried through all of these calcium channel types suggests a potentially significant mechanism by which activation of $\mu$-opioid receptors may control release of neurotransmitter from central endings of primary sensory afferent neurons and modulate transmission of nociceptive information entering the CNS.

\section{References}

Anwyl R (1991) Modulation of vertebrate neuronal $\mathrm{Ca}^{2+}$ channels by transmitters. Brain Res Rev 16:265-281.

Aosaki T, Kasai H (1989) Characterization of two kinds of high-voltage-activated calcium channel currents in chick sensory neurons. Pfluegers Arch 414:150-156.

Bean BP (1989) Classes of calcium channels in vertebrate cells. Annu Rev Physiol 51:367-384.

Dubel SJ, Starr TVB, Hell J, Ahlijanian MK, Enyeart JJ, Catterall WA, Snutch 'T (1992) Molecular cloning of the $\alpha_{-1}$ subunit of an omegaconotoxin $\mathrm{Ca}^{2+}$ channel. Proc Natl Acad Sci USA 89:5058-5062.

Dutar P, Rascol O, Lamour Y (1989) $\omega$-Conotoxin GVIA blocks synaptic transmission in the CAl field of the hippocampus. Eur J Pharmacol 174:261-266.

Gross RA, Macdonald RL (1987) Dynorphin A selectively reduces a large transient (N-type) calcium current of mouse dorsal root ganglion neurons in cell culture. Proc Natl Acad Sci USA 84:1-5.

Gundersen CB, Umbach JA (1992) Suppression cloning of the DNA for a candidate subunit of a presynaptic calcium channel. Neuron 9:527-537.

Hamill OP, Marty A, Neher E, Sakmann B, Sigworth SJ (1981) Improved patch-clamp techniques for high resolution current recording from cells and cell-free membrane patches. Pfluegers Arch 391:85100.

Hess P (1990) Calcium channels in vertebrate cells. Annu Rev Neurosci 13:337-356.

Hillyard DR, Monje VD, Mintz IM, Bean BP, Nadasdi L, Ramachandran J, Miljanich G, Azimi-Zoonooz A, McIntosh JM, Cruz LJ, et al. (1992) A new Conus peptide ligand for mammalian presynaptic $\mathrm{Ca}^{2+}$ channels. Neuron 9:69-77.

Lundy PM, Frew R, Fuller TW, Hamilton MG (1991) Pharmacological evidence for an omega-conotoxin, dihydropyridine-insensitive neuronal $\mathrm{Ca}^{2+}$ channel. Eur J Pharmacol 206:61-68.

Macdonald RL, Werz MA (1986) Dynorphin a decreases voltage-dependent calcium conductance of mouse dorsal root ganglion neurones. J Physiol (Lond) 377:237-249.

Meng F, Xie G, Thompson RC, Mansour A, Goldstein A, Watson SJ, Akil H (1993) Cloning and pharmacological characterization of a rat kappa-opioid receptor. Proc Natl Acad Sci USA 90:9954-9958.
Miller RJ (1992) Voltage-sensitive $\mathrm{Ca}^{2+}$ channels. J Biol Chem 267: $1403-1406$.

Mintz IM, Bean BP (1993) GABA-B receptor inhibition of P-type $\mathrm{Ca}^{2+}$ channels in central neurons. Neuron 10:889-898.

Mintz IM, Adams ME, Bean BP (1992a) P-Type calcium channels in rat central and peripheral neurons. Neuron 9:85-95.

Mintz IM, Venema VJ, Swiderek KM, Lee TD, Bean BP, Adams ME (1992b) P-type calcium channels blocked by spider toxin omegaAga-IVA. Nature 355:827-829.

Mogul DJ, Adams ME, Fox AP (1993) Differential activation of adenosine receptors decreases $\mathrm{N}$-type but potentiates $\mathrm{P}$-type $\mathrm{Ca}^{2+}$ current in hippocampal CA3 neurons. Neuron 10:327-334.

Moises HC, Rusin KI, Macdonald RL (1994a) Mu- and kappa-opioid receptors selectively reduce the same transient components of highthreshold calcium current in rat dorsal root ganglion sensory neurons. J Neurosci 14:5903-5916.

Moises HC, Rusin KI, Macdonald RL (1994b) Mu-opioid receptormediated reduction of neuronal calcium current occurs via a $G_{0}$-type GTP-binding protein. J Neurosci 14:3842-3851.

Murase K, Ryu PD, Randic M (1989) Excitatory and inhibitory amino acids and peptide-induced responses in acutcly isolated rat dorsal horn neurons. Neurosci Lett 103:56-63.

Nowycky MC, Fox AP, Tsien RW (1985) Three types of neuronal calcium channel with different calcium agonist sensitivity. Nature 316:440-443.

Plummer MR, Logothetis DE, Hess P (1989) Elementary properties and pharmacological sensitivities of calcium channels in mammalian peripheral neurons. Neuron 2:1453-1463.

Randall AD, Wendland B, Schweizer F, Miljanich G, Adams ME, Tsien RW (1993) Five pharmacologically distinct high voltage-activated $\mathrm{Ca}^{2+}$ channels in cerebellar granule cells. Soc Neurosci Abstr 19: 1478.

Regan LJ, Sah DWY, Bean B (1991) $\mathrm{Ca}^{2+}$ channels in rat central and peripheral neurons: high-threshold current resistant to dihydropyridine blockers and omega-conotoxin. Ncuron 6:269-280.

Sather WA, Tanabe T, Zhang JF, Mori Y, Adams ME, Tsien RW (1993) Distinctive biophysical and pharmacological properties of class A (BI) calcium channel $\alpha$, subunits. Neuron 11:291-303.

Schroeder JE, Fischbach PS, McCleskey EW (1990) T-type calcium channels: heterogenous expression in rat sensory neurons and selective modulation by phorbol esters. J Neurosci 10:947-951.

Schroeder JE, Fischbach PS, Zheng D, McCleskey EW (1991) Activation of $\mu$-opioid receptors inhibits transient high- and low-threshold $\mathrm{Ca}^{2+}$ currents, but spares a sustained current. Neuron 6:13-20.

Scroggs RS, Fox AP (1992) Calcium current variation between acutely isolated adult rat dorsal root ganglion neurons of different size. I Physiol (Lond) 445:639-658.

Snutch TP, Reiner PB (1992) $\mathrm{Ca}^{2+}$ channels: diversity of form and function. Curr Opin Neurobiol 2:247 253.

Thompson RC, Mansour A, Akil H, Watson SJ (1993) Cloning and pharmacological characterization of a rat mu-opioid receptor. Neuron 11:903-913.

Tsien RW, Ellinor PT, Horne WA (1991) Molecular diversity of voltage-dependent calcium channels. Trends Pharmacol Sci 12:349-354.

Wheeler DB, Tsien RW, Randall AD (1993) A calcium channel with novel pharmacology supports synaptic transmission and plasticity in the hippocampus. Soc Neurosci Abstr 19:909.

Wheeler DB, Randall AD, Tsien RW (1994) Roles of N-type and Q-type $\mathrm{Ca}^{2+}$ channels in supporting hippocampal synaptic transmission. Science 264:107-111.

Williams ME, Burst PF, Feldman DH́, Patthi S, Simerson S, Maroufi A, McCue AF, Veliçelebi G, Ellis SB, Harpold MM (1992a) Structure and functional expression of an omega-conotoxin sensitive N-type calcium channel. Science 257:389-395.

Williams ME, Feldman DH, McCue AF, Brenner R, Veliçelebi G, Ellis SB, Harpold MM (1992b) Structure and functional expression of $\alpha_{1}$, $\alpha_{2}$, and $\beta$ subunits of a novel human neuronal calcium channel subtype. Neuron 8:71-84.

Zhang JF, Randall AD, Ellinor PT, Horne WA, Sather WA, Tanabe T, Schwarz TL, Tsien RW (1993) Distinctive pharmacology and kinetics of cloned neuronal $\mathrm{Ca}^{2+}$ channels and their possible counterparts in mammalian CNS neurons. Neuropharmacology 32:10751088. 